\title{
Management of Laryngotracheal Stenosis by Laryngoplasty
}

\author{
GSN Murthy, R Bhimeshwar, M Veera Kumar, PSN Murthy, S Udaya Chanukya
}

\begin{abstract}
This is a prospective study done on six cases of laryngotracheal stenosis. They were operated by laryngoplasty with mucoperichondrial grafting stenting (temporary and permanent).

The purpose of the study was to determine the role of laryngoplasty in the treatment of acquired subglottic stenosis.

In this study, six patients who presented to the Government General Hospital from March 2011 to April 2012, with subglottic stenosis were enrolled. The details of their etiology, time period with endotracheal intubation, duration between extubation and onset of symptoms, treatment and postoperative recovery on follow-up were recorded and analyzed. It was found that laryngoplasty with cartilage grafting along with T-tube or Dumonts silicone stent placement carries good success rate, with no recurrence.
\end{abstract}

Keywords: Laryngotracheal stenosis, Subglottic stenosis, Acquired subglottic stenosis, Laryngoplasty, Montgomery T-tube, Dumonts stent, Laryngotracheal resection, Laryngotracheal reconstruction.

How to cite this article: Murthy GSN, Bhimeswar R, Kumar MV, Murthy PSN, Chanukya SU. Management of Laryngotracheal Stenosis by Laryngoplasty. Int J Phonosurg Laryngol 2013;3(2):46-50.

Source of support: Nil

Conflict of interest: None declared

\section{INTRODUCTION}

Acquired laryngotracheal stenosis is caused by prolonged intubation, high tracheostomy, polytrauma or an idiopathic entity. Compared to nonsubglottic tracheal stenosis which is best treated by laryngotracheal resection and end-toend anastomosis, treatment for laryngotracheal stenosis is technically challenging because of the narrow space and complex functions.

\section{History}

The Myer-Cotton staging system: Grade I lesions have less than $50 \%$ obstruction, grade II lesions have 51 to $70 \%$ obstruction, grade III lesions have 71 to $99 \%$ obstruction, and grade IV lesions have no detectable lumen or complete stenosis. ${ }^{1}$

The McCaffrey system: Stage I lesions are confined to the subglottis or trachea and are less than $1 \mathrm{~cm}$ long, stage II lesions are isolated to the subglottis and are greater than $1 \mathrm{~cm}$ long, stage III are subglottic/tracheal lesions not involving the glottis, and stage IV lesions involve the glottis. ${ }^{2}$

\section{Pathology}

The pathogenesis of acquired laryngotracheal stenosis is not completely understood but there are several theories that have been proposed. The most accepted theory proposes that stenosis results from wound healing in the areas of the airway which have undergone compression by an endotracheal tube or the cuff of a tube resulting in necrosis of the underlying mucosa and cartilage. This necrosis is a consequence of ischemia resulting from pressure from the tube or cuff exceeding the capillary pressure of the thin mucosa of the airway. Consequently, the normal mucociliary flow is disrupted which leads to infection in the perichondrium and then extends into cartilage. The cartilage may weaken and collapse, manifesting as tracheomalacia. Healing of the involved segment proceeds by secondary intention. This involves three temporally overlapping stages: an inflammatory stage, a proliferative stage, and a phase of contraction and remodeling.

\section{MATERIALS AND METHODS}

This prospective study was done on six patients who presented with laryngotracheal stenosis to Government General Hospital, Kakinada, Andhra Pradesh state, between March 2011 and April 2012. We took careful history about the onset and duration of symptoms followed by meticulous clinical examination, serological and radiological investigations. All the patients had a history of intubation following polytrauma or organophosphorus (OP) poisoning. One of the patients presented to the OPD with stridor and an emergency tracheostomy was performed. All were examined by videolaryngoscopy (Figs 1 and 2), direct laryngoscopy and investigated by MRI (Fig. 3) to know the level of stenosis.

All the patients underwent laryngoplasty involving mucoperichondrial grafting, followed by placement of Montgomery T-tube in two of them and permanent Dumon's silicone stent in the remaining four. All the cases were operated under general anesthesia. Intubation was done through the tracheostomy (elective in five and as emergency in one). A transverse neck incision was given at the level of cricoid cartilage (Fig. 4). The platysma and layers of subcutaneous tissues were separated. The laryngotracheal complex was exposed (Fig. 5) and then opened by a longitudinal incision (Fig. 6). The stenosed part was resected submucosally (Fig. 7). A mucoperichondrial autograft was obtained from the nasal septum. ${ }^{3}$ Grafting was done on both the anterior and posterior walls (Fig. 8). This was followed by the placement of the Montgomery T-tube placement (Fig. 9) in two patients and a Dumon's silicone tube in four patients (Table 1). Postoperatively, the 


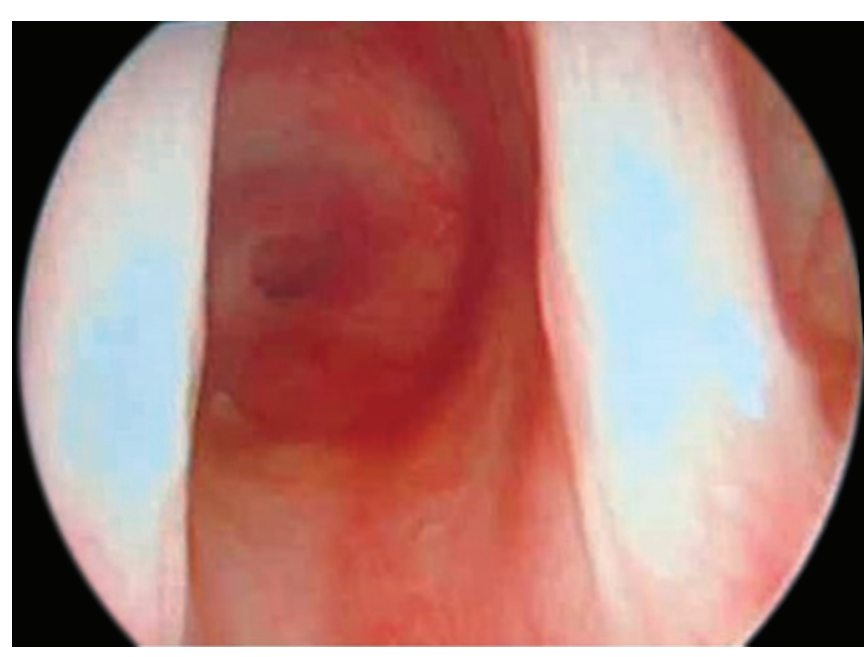

Fig. 1: Circumferential membranous narrowing of trachea

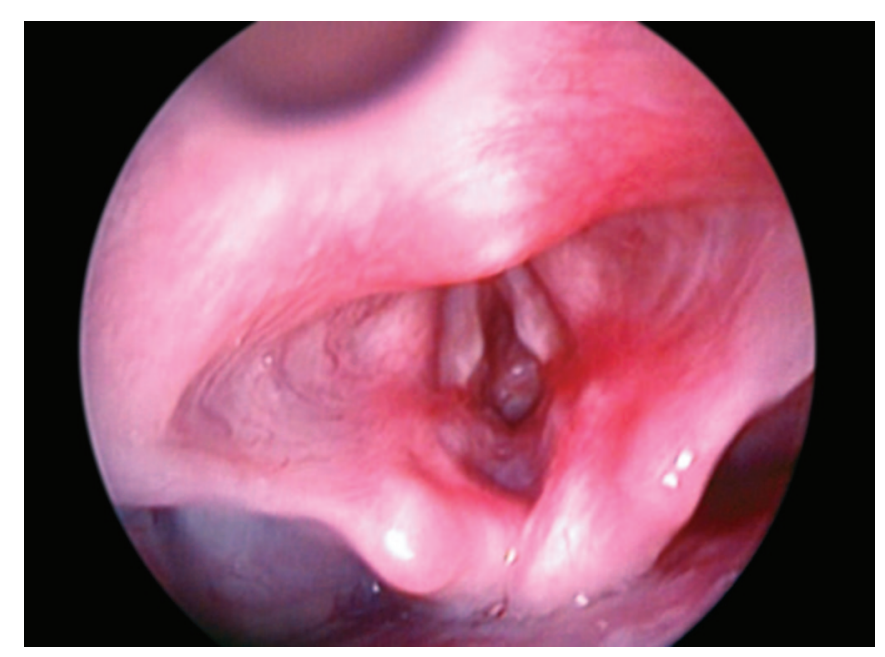

Fig. 2: Anterior tracheal wall stenosis with granulations

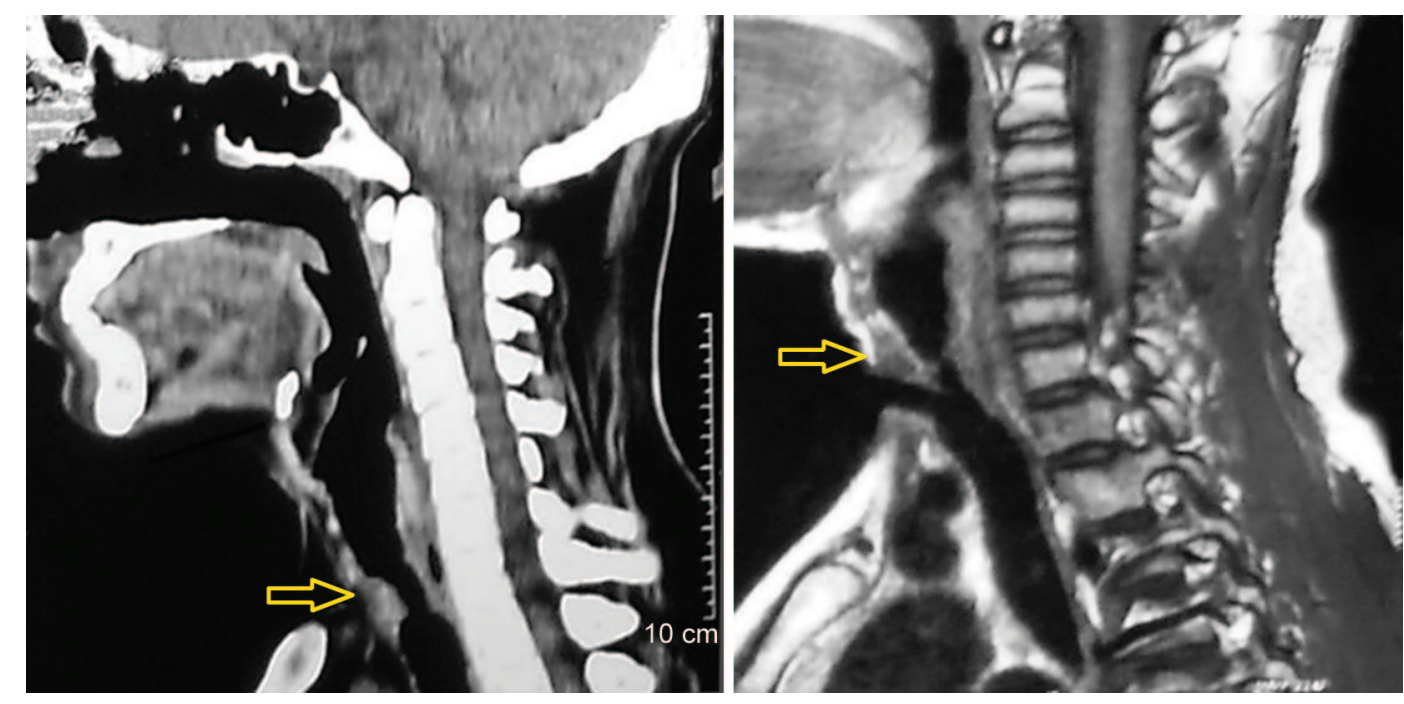

Fig. 3: Preoperative MRI films showing the stenosis (yellow arrows)

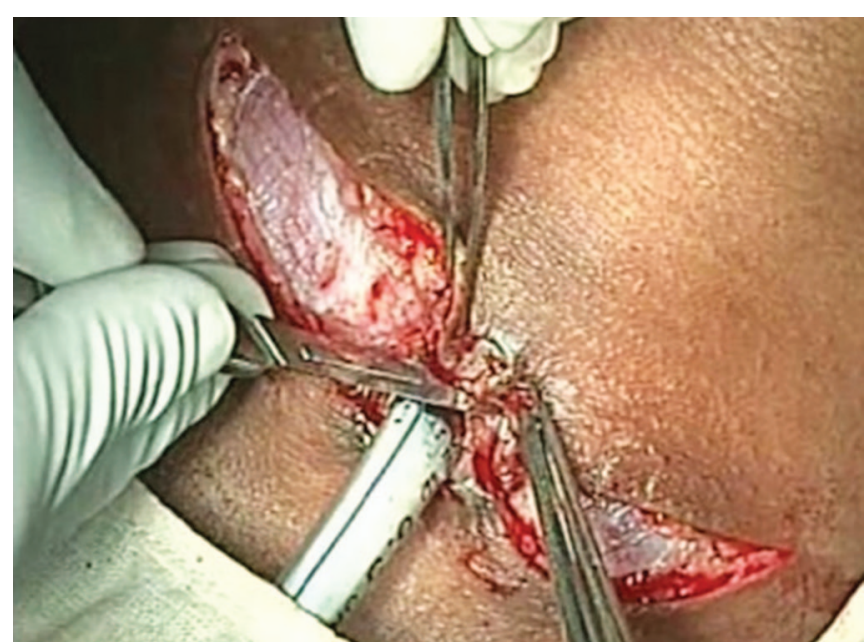

Fig. 4: Transverse neck incision

patients received broad spectrum antibiotics and analgesics and were monitored carefully in ICU. They were discharged after 15 days.

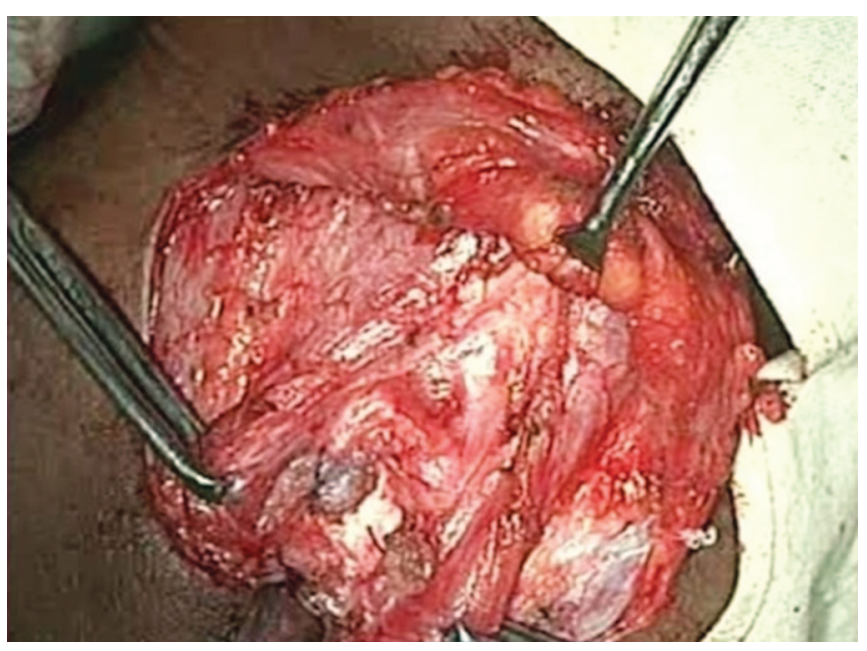

Fig. 5: Exposure of laryngotrachea

Follow-up was monthly, with videolaryngoscopy (Figs 10 and 11) performed at every visit. Postoperative X-ray and MRI (Fig. 11) were done after an interval of 6 months. 


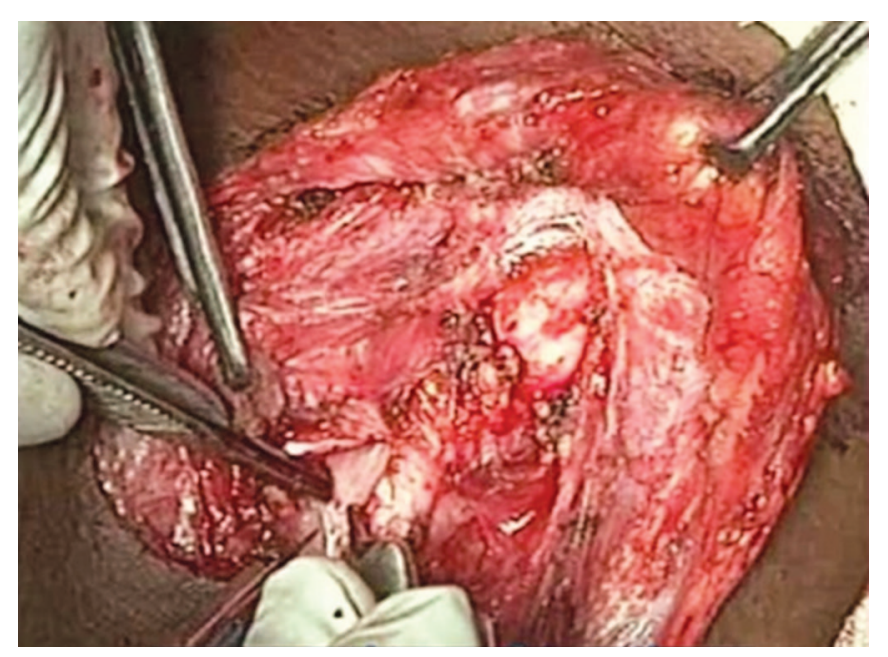

Fig. 6: Opening of trachea

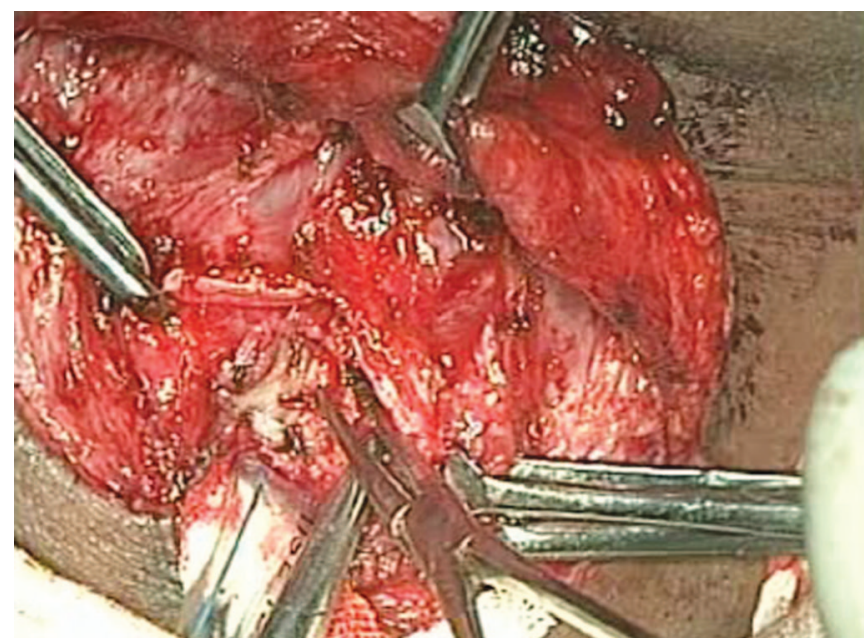

Fig. 8: Graft interposition

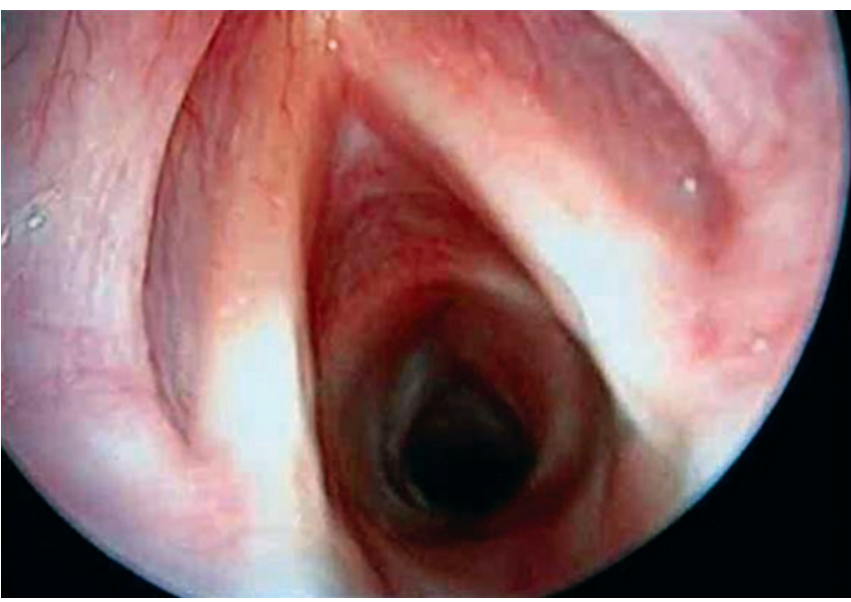

Fig. 10: Six months postoperative endoscopic view after the removal of T-tube

\section{OBSERVATIONS AND RESULTS}

The age of the patients ranged from 18 to 40 years. Four were males, and two, females. Prolonged intubation was the etiology in all cases. Length of the stenosis was

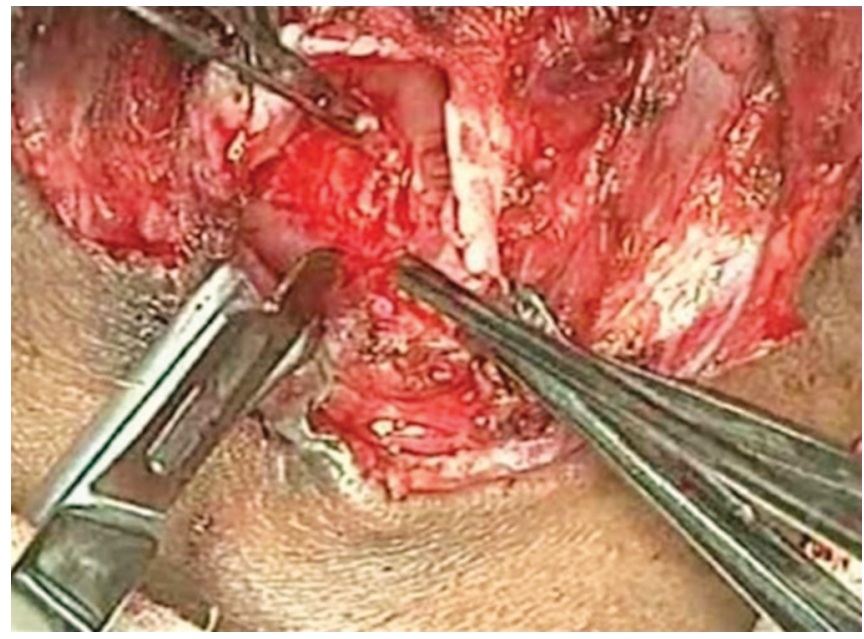

Fig. 7: Submucosal resection of stenosis

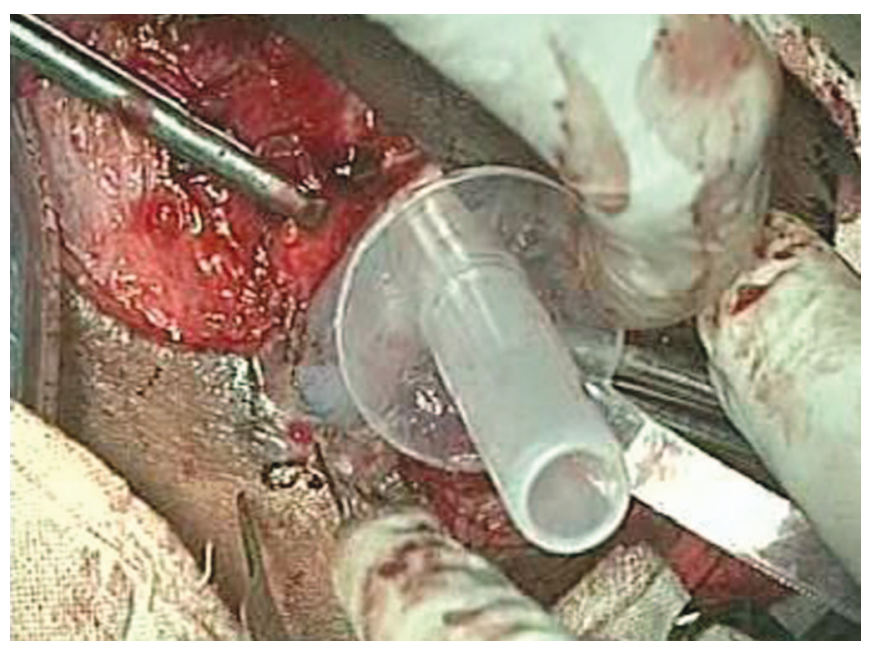

Fig. 9: Insertion of Montgomery T-tube

\begin{tabular}{|c|c|c|c|c|c|}
\hline $\begin{array}{l}\text { SI. } \\
\text { no }\end{array}$ & $\begin{array}{l}\text { Length of } \\
\text { lesion }\end{array}$ & $\begin{array}{l}\text { Treatment } \\
\text { plan }\end{array}$ & $\begin{array}{l}\text { Follow-up } \\
\text { period }\end{array}$ & $\begin{array}{l}\text { Cotton- } \\
\text { Myer's } \\
\text { stage }\end{array}$ & Recurrence \\
\hline 1. & $2 \mathrm{~cm}$ & $\begin{array}{l}\text { LP with } \\
\text { T-tube }\end{array}$ & 1 year & 3 & No \\
\hline 2. & $2 \mathrm{~cm}$ & $\begin{array}{l}\text { LP with } \\
\text { permanent } \\
\text { silicone } \\
\text { tube }\end{array}$ & $\begin{array}{l}11 / 2 \\
\text { year }\end{array}$ & 3 & No \\
\hline 3. & $3 \mathrm{~cm}$ & $\begin{array}{l}\text { LP with } \\
\text { permanent } \\
\text { silicone } \\
\text { tube }\end{array}$ & $\begin{array}{l}11 \\
\text { months }\end{array}$ & 3 & No \\
\hline 4. & $3 \mathrm{~cm}$ & $\begin{array}{l}\text { LP with } \\
\text { permanent } \\
\text { silicone } \\
\text { tube }\end{array}$ & $\begin{array}{l}11 / 2 \\
\text { year }\end{array}$ & 3 & No \\
\hline 5. & $2 \mathrm{~cm}$ & $\begin{array}{l}\text { LP with } \\
\text { T-tube }\end{array}$ & 1 year & 3 & No \\
\hline 6. & $2 \mathrm{~cm}$ & $\begin{array}{l}\text { LP with } \\
\text { permanent } \\
\text { silicone } \\
\text { tube }\end{array}$ & $\begin{array}{l}11 / 2 \\
\text { year }\end{array}$ & 3 & No \\
\hline
\end{tabular}



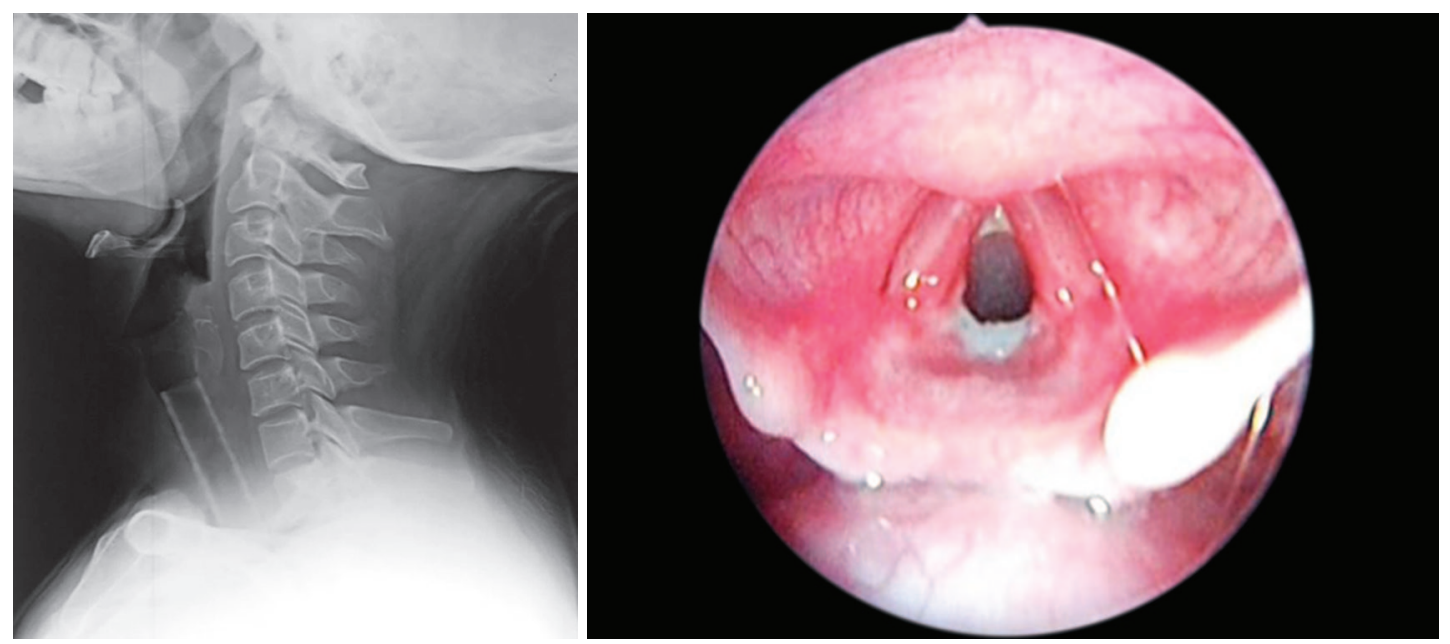

Fig. 11: Postoperative X-ray neck and endoscopic view of Dumon's stent

assessed by videolaryngoscopy and MRI scan. Laryngeal framework was normal in all the patients. All the patients underwent laryngoplasty with grafting and stent placement. The patients with Montgomery T-tube in situ were admitted after thorough follow-up for 6 months and the T-tube was removed. The patients with the Dumon's Teflon stent in situ were followed up regularly.

None of the patients had any significant postoperative complication. They were able to breathe and function normally, with no features of recurrence until last visit (Table 1).

\section{DISCUSSION}

In the present day, scenario of increased road traffic accidents and advanced life support systems in the management of OP cases with prolonged periods of intubation, the incidence of subglottic stenosis is rising. Traumatic/repeated intubations, prolonged intubations, intubation in situ with high pressure in the cuff, oversized endotracheal tube may be the possible factors responsible for this. Early tracheostomy, proper type of the tube, maintenance of complete sedation of intubated patients, careful monitoring of the cuff pressure of the ET tube can be helpful in reducing the incidence of stenosis.

Unfortunately, many of these patients are misdiagnosed as asthma or COPD before the true cause is identified. A high index of suspicion is needed in view of onset of respiratory symptoms following intubation regardless of the duration. ${ }^{1}$

As it is a new and emerging disease, the treatment of laryngotracheal stenosis provides a challenge for the otolaryngologist. Optimum treatment of such lesions is controversial with the availability of various modalities of treatment. Endoscopic dilatation used in mild grades has had limited success. ${ }^{4}$ Endoscopic laser excision proved to be effective in treating the condition but its usage is limited to stenosis of less than $1 \mathrm{~cm}$, carrying the disadvantages of thermal injury to the adjacent area and delayed maturation of collagen in laser wounds. ${ }^{5}$ The technique of cricotracheal resection with end-to-end anastomosis has a fair success rate but the unpredictability of the fate of the anastomosis, high chances of anastomotic failure with serious complications plague this technique. ${ }^{6}$ Laryngoplasty with mucoperichondrial grafting and placement of stents is as effective as cricotracheal resection but with lesser complications. The wire mesh metallic stents used earlier faced failure with growth of granulations. The anterior and posterior grafting gives a chance of mucosal growth and the placement of stents ensures the apposition of the graft on the tracheal walls and maintains the patency of the airway.

\section{CONCLUSION}

It is too short a time to come to a conclusion with the limited experience of six cases in a one and half year period. However, our success rate has been $100 \%$ with laryngoplasty with mucoperchondrial grafting with placement of a temporary T-tube or a permanent indwelling stent. We propose that this is an equally good, if not better, way of management of laryngotracheal stenosis.

\section{REFERENCES}

1. Myer CM, Cotton RT, Short SR. The Pediatric Airway. ed. Lippincott William \& Wilkins; 1995. p. 68-70.

2. McCaffrey TV. Classification of laryngotracheal stenosis. Laryngoscope 1992 Dec;102(12 Pt 1):1335-1340.[Medline].

3. Terra RM, Minamoto H, Carneiro F, Pego-Fernandes PM, Jatene FB. Laryngeal split and rib cartilage interpositional grafting: treatment option for glottic/subglottic stenosis in adults. J Thorac Cardiovasc Surg 2009 Apr;137(4):818-823. [Medline]. 
4. Lee KH, Rutter MJ. Role of balloon dilation in management of adult idiopathic subglottic stenosis. Ann Otol Rhinol Laryngol 2008 Feb;117(2):81-84. [Medline].

5. Dedo HH, Sooy CD. Endoscopic laser repair of posterior glottic, subglottic and tracheal stenosis by division or micro-trapdoor flap. Laryngoscope 1984 Apr;94(4):445-450. [Medline].

6. Therapeutic approach and results in the treatment of subglottic tracheal stenosis. Med Pregl 2000 Jul-Aug;53(7-8):349-353.

\section{ABOUT THE AUTHORS}

\section{GSN Murthy (Corresponding Author)}

Professor and Head, Department of ENT, Head and Neck Surgery Rangaraya Medical College, Kakinada, Andhra Pradesh, India e-mail: drgsnent@gmail.com

\section{R Bhimeshwar}

Assistant Professor, Department of ENT, Head and Neck Surgery Rangaraya Medical College, Kakinada, Andhra Pradesh, India

\section{Veera Kumar}

Assistant Professor, Department of ENT, Head and Neck Surgery Rangaraya Medical College, Kakinada, Andhra Pradesh, India

\section{PSN Murthy}

Professor and Head, Department of ENT, PSIMS and RF, Vijayawada, Andhra Pradesh, India

\section{S Udaya Chanukya}

Junior Resident, Department of ENT, Head and Neck Surgery Rangaraya Medical College, Kakinada, Andhra Pradesh, India 